RASĀYAN J. Chem.

Vol. 13 | No. 1 |733 - 738| January - March | 2020 ISSN: 0974-1496 | e-ISSN: 0976-0083 | CODEN: RJCABP

\title{
DEVELOPMENT OF COMPLEX FERTILIZER TECHNOLOGY WITH IMPROVED AGROCHEMICAL PROPERTIES USING HYDROGEL
}

\author{
Raikhan ZH. Omirova, ${ }^{1, *}$, Aidar A. Bolysbek ${ }^{2}$, Shavkat D. Shirinov ${ }^{3}$ \\ and Abdulakhat T. Dzhalilov ${ }^{4}$ \\ ${ }^{1,2}$ Department of Chemical Technologies of Inorganic Substances of M.Auezov South \\ Kazakhstan \\ Kazakhstan State University, 160012, Shymkent, Kazakhstan \\ ${ }^{3,4}$ Tashkent Scientific Research Institute of Chemical Technology, Tashkent, Uzbekistan \\ *E-mail:nauka3524@gmail.com
}

\begin{abstract}
The article presents the results of obtaining hydrogels based on polyacrylonitrile, with potassium-phosphorus fertilizers in the composition used as agricultural fertilizers. As a potassium-phosphate fertilizer used fertilizer potassium dehydrogenase orthophosphate. Comparative analysis was carried out using the obtained hydrogel cultures of wheat, safflower and barley. It is established that the polymer hydrogel containing potassium and phosphorus increases the moisture content of the soil, improves its water-retaining properties, improves the process of air exchange, increases the water-resistance of soil aggregates, and increases the productivity of plants while reducing the amount of polymer hydrogel per hectare. In this work, it was obtained a hydrogel containing potassium, magnesium and phosphorus impregnated by mixing with the addition of the same amount of the hydrogel, with the addition of soluble caliciviridae and magnetohydrostatic. In the drying Cabinet, increased twice the volume obtained, dried for two hours at a temperature of $90-95^{\circ} \mathrm{C}$. Several samples containing potassium, magnesium and phosphorus were sampled for plants.
\end{abstract}

Keywords: Hydrogel, Macro and Microelement Containing Fertilizers, Water Solution, Soil, Fertilizer Properties.

(C) RASĀYAN. All rights reserved

\section{INTRODUCTION}

The country ranks 9 th in the area in 246 countries $(2,724,900 \mathrm{~km} 2)$. Almost 100 million hectares of this area is empty, and $44 \%$ of the water deficit. It is a country that geographically occupies Central Asia with Eastern Europe. Also, part of Eastern Europe consists of semi-desert and desert beams. The basic grain culture-wheat, you get half of the total acreage. The cultivation of wheat is of great importance to soil and heat. The fertile black earth zone occupies a large part of the region. Turkestan region is a large region in the South of Kazakhstan, engaged in irrigated agriculture, developed animal husbandry and occupies an important place to provide the Republic with food. In this regard, based on the words of the head of state, it is necessary to develop agriculture in the Turkestan region, increasing soil fertility.

Water-soluble polymers will be widely used in various industries of developed countries and agriculture. However, the country has not studied enough high-molecular compounds with such properties. Therefore, the study of the technology of obtaining new water-soluble polymers for the development of agriculture is a requirement of the time. ${ }^{1-3}$ To this end, this work has studied the effectiveness of hydrophobic, hydrophobic, absorbing moisture, with the addition of effective fertilizers for agriculture, based on their propensity to temperature.

Due to the lack of macro-and microelements in the soil, the yield of plants is reduced and the quality is reduced. Phosphorus accelerates the maturation of plants. Under the influence of phosphorus, fertilizers crops ripen in 5-7 days, plant roots are well suchat, deepen and grow. When a deficiency of phosphorus

Rasayan J. Chem., 13(1), 733-738(2020)

http://dx.doi.org/10.31788/RJC.2020.1315651

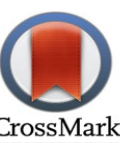




\section{RASĀYAN J. Chem.}

Vol. 13 | No. 1 |733 - 738| January - March | 2020

absorption of oxygen is slowed down, change liberalization of the system of oxidation outside of mitochondria (oxidase it is determined to tend the acid, askorbinska). With an insufficient amount of nitrogen in the soil slows plant growth, to change the greenness of the leaves, disturbed the totality of biochemical processes, dramatically reducing the yield of the crop. Well-provided potassium plants are resistant to fungal and bacterial diseases. Leaves of vegetative plants grown under conditions of potassium, a yellowish starting from the bottom up. Them later edges and the ends dry out and shrink. Due to the lack of copper in the soil plants do not develop properly and contribute to a sharp decrease in productivity. The lack of chalk has a negative impact on the growth of pollen tubes, reduces the yield of seeds (rotting of the sugar beet core, flax bacteria), leads to plant disease. When zinc deficiency occurs, the disease called female disease (the leaves of the trees get enough sleep). According to the results of studies, trace elements in the soil affect the productivity of plants and animals and occupy an important place in human health. ${ }^{4-6}$

The experiment aimed to study the use of hydrogels derived from starch, vinyl monomers, minerals, CMC and HIPAN and the potential effect of the used hydrogel on plant growth and development productivity.

Laboratory work has been tested in the laboratory of the department chemical technology of inorganic substances, M. Auezov South Kazakhstan state university and Physico-chemical analyses were performed in the Regional Laboratory Test Engineering Profile (RLTEP) based on the M. Auezov South Kazakhstan state university.

In this work, it was obtained a hydrogel containing potassium, magnesium and phosphorus impregnated by mixing with the addition of the same amount of the hydrogel, with the addition of soluble caliciviridae and magnetohydrostatic. In the drying Cabinet, increased twice the volume obtained, dried for two hours at a temperature of $90-95^{\circ} \mathrm{C}$.

\section{EXPERIMENTAL}

Several samples containing potassium, magnesium and phosphorus were sampled for plants. Samples are placed in four identical tanks, and the first dishes are placed digidrogenfosfat potassium and magnesium, in the second the dishes are placed only hydrogel, the fourth-ware-hydrogel with potassium, magnesium and phosphorus a few days later the ascent of plants began. Plants in these containers were not supplied with water. Figure-1 shows the view after a while.
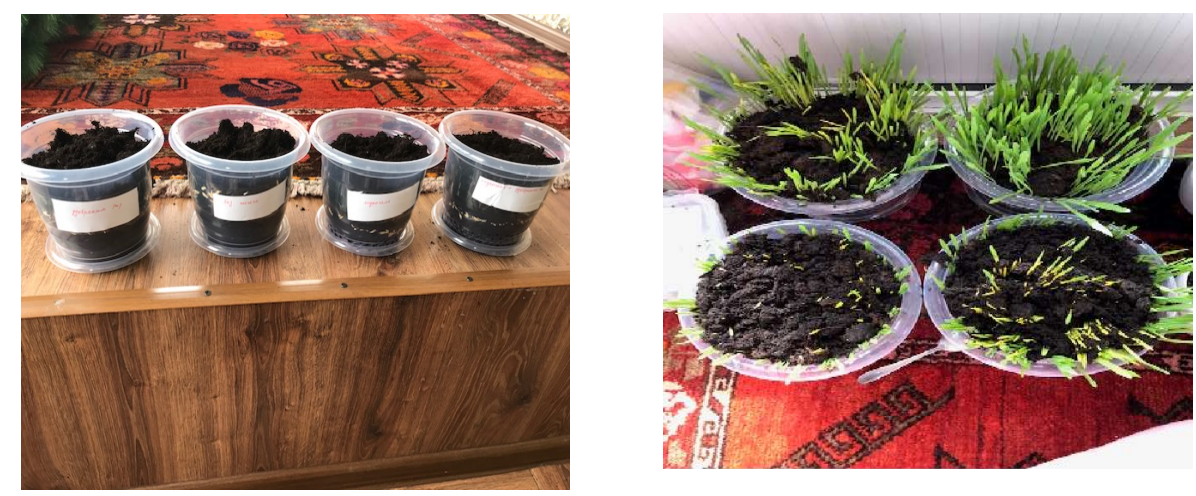

Fig.-1: Filled with Soil, The Origin of the Plants in the Container

Figures-1 to 2 can determine the productivity and durability of plants in containers containing potassium, magnesium and phosphorus.

Under the influence of several negative factors, such as global climate change, environmental degradation, in recent years, rainfall on earth has decreased, and water scarcity has become a global problem. Without water, the land beyond the harvest, the hay is not growing, the cattle are stabiliziruemost. According to the studied data, drought occurs every 6-8 years until 2000, in subsequent periods, this situation is repeated in 2-3 years. This has a negative impact on agricultural productivity. Therefore, in our vast land there is a need for the introduction of modern and fast irrigation technologies. 


\section{RASĀYAN J. Chem.}

Vol. 13 | No. 1 |733 - 738| January - March | 2020

To solve these problems, the issues of rational use of water resources, including precipitation, prevention of water losses were considered. ${ }^{7}$ Studies of foreign scientists and world experiments show that the use of polymer hydrogels for water with different chemical bases, is the most effective method of saving water, including if its composition introduced macro-holders and chips, as well as provided that fertilizers are supplied only in the required amount.
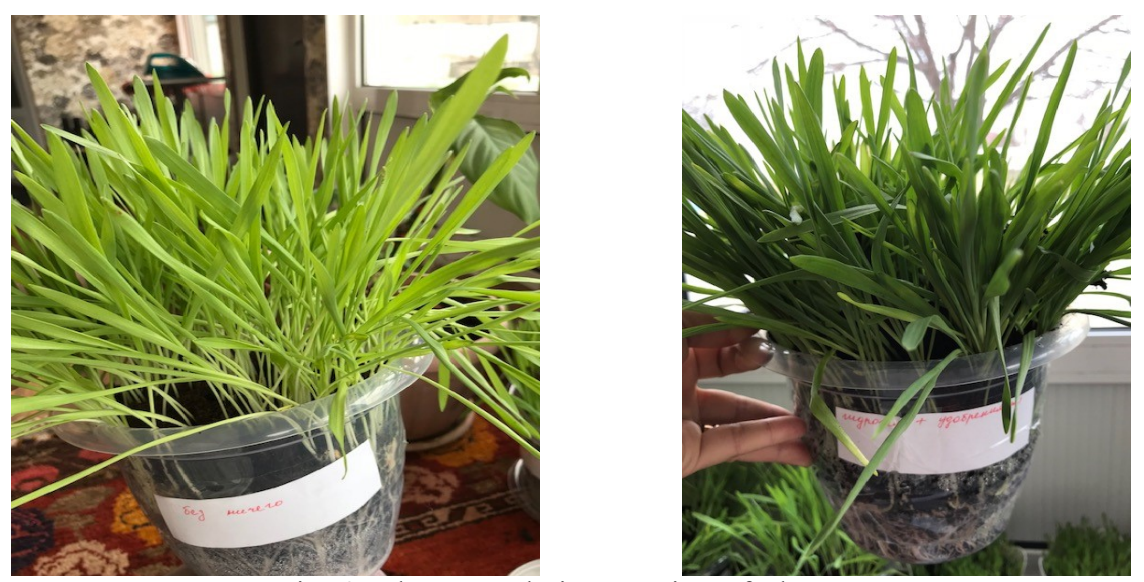

Fig.-2: Plant Population, Drying of Plants

Hydrogel containing potassium phosphorus is laid in parallel with seed sowing. One hectare of land consumes 35-50 kilograms of hydrogel. Here it is necessary to pay attention to its smooth distribution at a depth of 20-30 centimeters. Based on our test results, when using hydrogel in the field, it does not lose its properties for 2-3 years. Products caused by the decay of obsolete hydrogel do not violate the infrastructure of the earth and are transferred to plants as fertilizers. At the same time, it should be noted as a waste-free technology, since the possibility of using it remains for a long time. In short, the use of hydrogel in the country will save $20-40 \%$ of water spent on the irrigation of crops.

The above classification, like any other, is rather conditional, and certain elements in the works of different authors sometimes fall into different groups. Also, in the tissues of some plant species, individual trace elements are contained in quantities characteristic of macronutrients. Nevertheless, for practical purposes, i.e. the organization of mineral nutrition of plants in economic conditions, this classification is quite convenient and allows you to adequately assess the role of these or other elements in the harvest, to choose the right methods to fill their shortage in the soil.

Macroelements and microelements are necessary for a plant in rather large quantities because they are "building material", first of all, for proteins. Microelements are a part of enzymes, vitamins, etc. Normal development and functioning of both individual cells and the whole plant organism are impossible without the optimal provision of elements of all these groups.

The absence or lack of any of the elements necessary for growth and reproduction causes quite certain symptoms of starvation. However, by doing higher doses, macro-and micronutrients become toxic for plants and consuming them of people and animals.

Nutrients in the root nutrition of the plant are obtained from the soil. The main sources of micronutrients in the soil are parent soil-forming rocks. In this case, the soil is very different in the content of trace elements. So, in moraine loess-like loam content of cobalt, chromium, strontium 2 to 2.5 times more, and Nickel, vanadium, titanium, barium, boron, manganese 3 to 4 times more than in the Sands. Peat-marsh soils are poor in trace elements. At the same time, the content of trace elements in the soil increases with the accumulation of organic substances in it. That is, when manure, compost and other organic fertilizers are applied, the soil is enriched not only with macro -, but also with microelements.

The solubility of trace elements in soils is important for their biological availability and ability to move. Heavy soils (both alkaline and neutral) retain trace elements well and therefore slowly supply them to plants, which can lead to a shortage of some elements. Light soils, on the contrary, can be a source of readily available trace elements, but at the same time, their supply is depleted faster. Therefore, when 
RASĀYAN J. Chem.

Vol. 13 | No. 1 |733 - 738| January - March | 2020

assessing the availability of soil micronutrients it is important to take into account not only their gross content but also the presence of mobile forms. Moreover, the difference between these two values can be very significant.

For example, boron in mobile form is only $2-4 \%$ of the gross content of this trace element, copper, molybdenum, cobalt, and zinc10-15\%. Soil micronutrient availability varies during the growing season, and also depends on the intensity of precipitation, evaporation of moisture from the soil, etc. Depending on these factors, the concentration of trace elements in soil solutions may vary more than 10 times. This should be taken into account when carrying out soil analyses. In this case, the concentration of macronutrients, although also dependent on these factors, varies to a lesser extent.

The transfer of dissolved elements in the soil can occur in two ways: through the soil solution (diffusion) and together with the moving soil solution (leaching). Depending on the climate, this process has its characteristics. Thus, in a cool humid climate, the leaching of trace elements down the soil profile is more pronounced than their accumulation. And in a warm dry climate more characteristic upward movement of trace elements.

\section{RESULTS AND DISCUSSION}

As a result, there is a significant increase in the period of soil moisture; moisture capacity depends on the type of polymer, soil texture and size of granules, the salinity of the soil solution and the presence of ions. Another advantage of LNG in conditions of natural soil moisture is metamorphosed into large plate aggregates with a diameter of $5-10 \mathrm{~mm}$, of irregular shape, in which up to $80-85 \%$ of soil moisture is retained by the type of freely bound, thereby creating favorable conditions for the development of the root system. Polymers were first introduced for agricultural use in the early 1980s. There are three main types of hydrogels that have been developed as agricultural polymers:

1. Starch-grafted copolymers obtained by grafted polymerization of polyacrylonitrile to starch followed by saponification of Acrylonitrile unit;

2. Crosslinked polyacrylate;

3. Cross-linked polyacrylamides and cross-linked acrylamide copolymers containing a major percentage of acrylamide units.

Most of the hydrogels on the market for agriculture come from the latter group, as they are said to remain active for a much longer time. Depending on their natural or synthetic origin and the method of preparation, hydrogels are classified of hydrogels. Also, depending on their physical structure and chemical composition are divided into:

a. Amorphous (non-crystalline)

b. Semi-crystalline: a complex mixture of amorphous and crystalline phases

c. Crystal

There are two ways of introducing hydrogels into the soil:

1. Introduction in dry form. The dry polymer is introduced into the subsurface by mixing with sandy soil at a depth of about $15-25 \mathrm{~cm}$ and then wetting to swell before cultivation. Once the polymer swells the soil structure improves and the water penetration and retention capacity increases, the surface water runoff and erosion decreases. This method is used for long-term use because the absorption of water polymers need a long time.

2. Introduction in wet form. The polymer solution is sprayed on a pre-moistened top layer of soil, after drying to create water-line units that prevent soil erosion. This method is particularly well suited for immediate sowing, and can also be used to reduce water consumption in irrigation systems where water losses occur due to the weak ability of the soil to retain moisture. As well as to reduce soil erosion, it is used in the upper layers of the soil.

The surface has a positive effect on the stability of the aggregate, hydraulic conductivity and distribution of air conditioners. Thus, polymers have a positive effect on the soil and improve the water-physical properties of the soil. Application to the soil improves the characteristics of the soil and it remains productive for a long time, even for 4-5 years.

For crops of great importance are potassium and phosphorus. Due to the lack of fertilizer plants are exposed to various diseases, which lead to a decrease in production. Since potassium and phosphorus add 
RASĀYAN J. Chem.

Vol. 13 | No. 1 |733 - 738| January - March | 2020

direct nutritional value, which has a significant impact on performance in various ways. ${ }^{8}$ Also, hydrogels containing potassium and phosphorus improve their properties as a fertilizer for carbonate and saline soils. Typically, the size and dispersion of hydrogel granules directly affect the properties of the particles. Potassium dihydro orthophosphate soluble in this research has 5:1, 5:2, 5:3, 5:4 in contact with water and mixed in the same amount by mixing with the hydrogel obtained hydroxide containing impregnated with potassium and phosphorus.
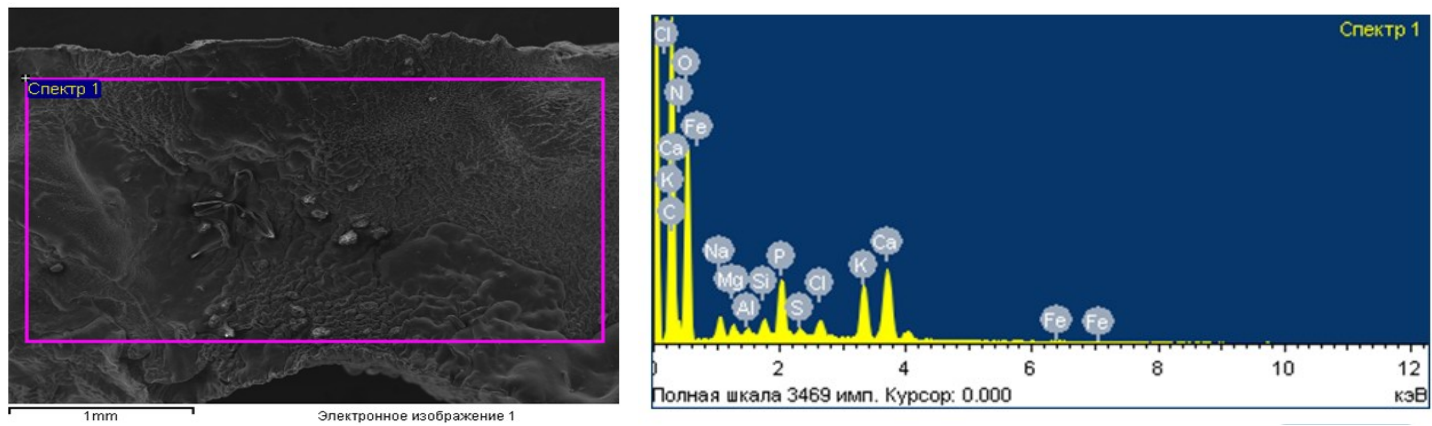

Fig.-3: Results of Spectral Analysis

Figure-3 the desiccator, increased twice the volume obtained, dried for two hours at a temperature of 90$95^{\circ} \mathrm{C}$. The hydrogel containing potassium and phosphorus dried. In the accredited laboratory of M.Auezov SKSU. conducted elemental examination and analysis of the infrared spectrum. The results of the spectral and element-by-element analysis show the presence of potassium and phosphorus, as well as a small amount of magnesium.

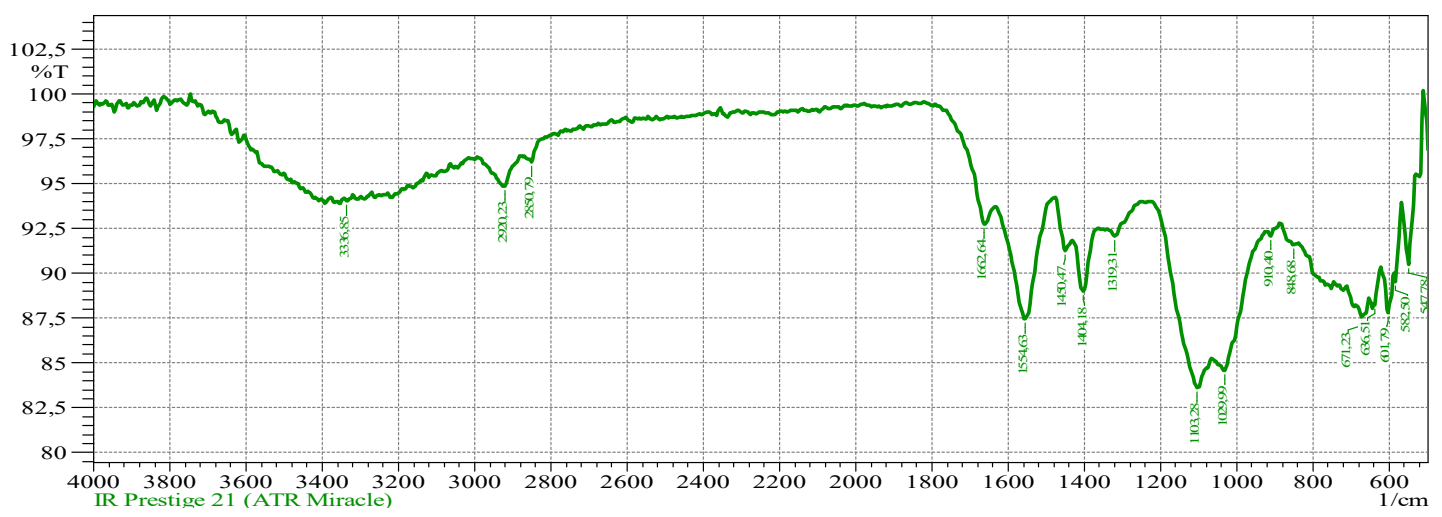

Fig.-4: Infrared Spectral Analysis of Hydrogel Containing Nitrogen, Potassium and Phosphorus Table-1: The Peaks of the IR Spectrum

\begin{tabular}{|l|l|l|l|l|l|l|l|}
\hline No. & Peak & Intensity & $\begin{array}{c}\text { Corr. } \\
\text { Intensity }\end{array}$ & Base (H) & Base (L) & Area & Corr. Area \\
\hline 1 & 547,78 & 90,509 & 3,946 & 563,21 & 532,35 & 1,065 & 0,316 \\
\hline 2 & 582,50 & 89,545 & 1,238 & 586,36 & 567,07 & 0,719 & 0,052 \\
\hline 3 & 601,79 & 87,795 & 2,251 & 621,08 & 590,22 & 1,573 & 0,173 \\
\hline 4 & 636,51 & 88,236 & 1,268 & 651,94 & 624,94 & 1,393 & 0,092 \\
\hline 5 & 671,23 & 87,554 & 0,868 & 686,66 & 651,94 & 1,937 & 0,089 \\
\hline 6 & 848,68 & 91,583 & 0,193 & 883,40 & 844,82 & 1,414 & 0,047 \\
\hline 7 & 910,40 & 92,055 & 0,374 & 918,12 & 887,26 & 1,058 & 0,023 \\
\hline 8 & 1029,99 & 84,570 & 2,398 & 1064,71 & 921,97 & 7,816 & 0,576 \\
\hline 9 & 1103,28 & 83,597 & 3,459 & 1230,58 & 1068,56 & 8,986 & 1,208 \\
\hline 10 & 1319,31 & 92,090 & 0,727 & 1338,60 & 1253,73 & 2,678 & 0,109 \\
\hline 11 & 1404,18 & 89,019 & 3,095 & 1431,18 & 1365,60 & 2,742 & 0,427 \\
\hline 12 & 1450,47 & 91,281 & 1,395 & 1477,47 & 1435,04 & 1,497 & 0,140 \\
\hline 13 & 1554,63 & 87,458 & 6,519 & 1631,78 & 1481,33 & 6,134 & 2,075 \\
\hline 14 & 1662,64 & 92,746 & 2,112 & 1762,94 & 1635,64 & 2,376 & 0,324 \\
\hline 15 & 2850,79 & 96,230 & 0,685 & 2870,08 & 2816,07 & 0,746 & 0,047 \\
\hline 16 & 2920,23 & 94,852 & 1,490 & 2970,38 & 2881,65 & 1,738 & 0,294 \\
\hline 17 & 3336,85 & 94,058 & 0,150 & 3340,71 & 3321,42 & 0,503 & 0,011 \\
\hline
\end{tabular}




\section{RASĀYAN J. Chem.}

Vol. 13 | No. 1 |733 - 738| January - March | 2020

As shown in Fig.-4 and Table-1, the resulting hydrogel contains nitro compounds, organophosphorus compounds and carboxylic acids. Peaks between 547-910 prove the presence of silicate compounds. Under the influence of several negative factors, such as global climate change, environmental degradation, in recent years, rainfall on earth has decreased, and water scarcity has become a global problem. Without water, the land beyond the harvest, the hay is not growing, the cattle are stabiliziruemost. According to the studied data, drought occurs every 6-8 years until 2000 , in subsequent periods, this situation is repeated in 2-3 years. This has a negative impact on agricultural productivity. Therefore, on our vast land, there is a need for the introduction of modern and fast irrigation technologies. In our research work, we considered the issues of rational use of water resources, including precipitation, prevention of water losses to solve these problems. Studies of foreign scientists and world experiments show that the use of polymer hydrogels for water with different chemical bases, is the most effective method of saving water, including if its composition introduced macro-holders and chips, as well as provided that fertilizers are supplied only in the required amount. The hydrogel containing potassium phosphorus is laid in parallel with seed sowing. One hectare of land consumes 35-50 kilograms of the hydrogel. Here it is necessary to pay attention to its smooth distribution at a depth of 20-30 centimeters. Based on our test results, when using hydrogel in the field, it does not lose its properties for 2-3 years. Products caused by the decay of obsolete hydrogel do not violate the infrastructure of the earth and are transferred to plants as fertilizers. At the same time, it should be noted as a waste-free technology, since the possibility of using it remains for a long time. In short, the use of hydrogel in the country will save 20$40 \%$ of water spent on the irrigation of crops.

\section{CONCLUSION}

The work made several conclusions on increasing the yield of grain, safflower and barley crops used in agriculture:

- The provision of sufficient water for grain, Safonov and barley

- Providing fertilizers, i.e. potassium and phosphorus elements at the level necessary for wheat, safflower and barley

- No cost for the fertilizers after the harvest

- Despite the aridity, in the spring month before the crops

- The presence of looseness of the soil composition due to edema and emptying of the hydrogel.

As a result, polymer hydrogel - hydrogel, containing macro-and microelements, is an increase in soil moisture capacity, improving water-protective properties, improving the process of air exchange, increasing the water-resistance of soil aggregates with a decrease in the content of polymer hydrogel per hectare of land, as well as increasing the productivity of plants.

\section{REFERENCES}

1. I. Gustian, Ghufira and D. Oktiarni, Rasayan Journal of Chemistry, 12(1), 284(2019), DOI: $10.31788 /$ RJC.2019.1215010

2. E. A. Aubakirov, K. E. Burkhanbekov, M. F. Faizullaeva and Zh. K. Shomanova, Solid Fuel Chemistry, 50(4), 220(2016), DOI:10.3103/s0361521916040091

3. H. Omidian, J. G. Rocca, K. Park, Journal of Controlled Release, 112(1),3(2005), DOI: 10.1016/j.jconrel.2004.09.028

4. B. F. Fedyushkin, Chemistry, Technology and Application of Substances 4, 272 (1989).

5. R. Z. Omirova, A. A. Bolysbek, S. D. Shirinov, A. T. Dzhalilov, Rasayan Journal of Chemistry 12, (4), 2047(2019), DOI: 10.31788/RJC.2019.1245331

6. V. M. Shevko, A. D. Badikova, D. D. Amanov, G. E. Karataeva, B. A. Lavrov, Rasayan Journal of Chemistry, 11 (3), 1050(2018), DOI: 10.31788/RJC.2018.1132038

7. Liu Xinxing, Zhen Tong, Hu Ou, Macromolecules, 28, 3813(1995).

8. A. Kaushik, S. Arya, A.Vasudev and S. Bhansali, Open Journal of Applied Biosensor, 2, 134(2013).

9. A. M. Blodgett, D. J. Beattis, J. W. White, HortTechnology, 5 (1), 38(1993).

[RJC-5651/2019] 